\title{
UCRL-TR-226008
}

LA W REN CE LIVERMORE N A T IO N A L LABORATORY

Developing Livestock Facility Type Information from USDA Agricultural Census Data for Use in Epidemiological and Economic Models

Carl Melius, Alix Robertson, Pam Hullinger

November 10, 2006 
This document was prepared as an account of work sponsored by an agency of the United States government. Neither the United States government nor Lawrence Livermore National Security, LLC, nor any of their employees makes any warranty, expressed or implied, or assumes any legal liability or responsibility for the accuracy, completeness, or usefulness of any information, apparatus, product, or process disclosed, or represents that its use would not infringe privately owned rights. Reference herein to any specific commercial product, process, or service by trade name, trademark, manufacturer, or otherwise does not necessarily constitute or imply its endorsement, recommendation, or favoring by the United States government or Lawrence Livermore National Security, LLC. The views and opinions of authors expressed herein do not necessarily state or reflect those of the United States government or Lawrence Livermore National Security, LLC, and shall not be used for advertising or product endorsement purposes.

This work performed under the auspices of the U.S. Department of Energy by Lawrence Livermore National Laboratory under Contract DE-AC52-07NA27344. 


\section{Developing Livestock Facility Type Information from USDA Agricultural Census Data for Use in Epidemiological and Economic Models}

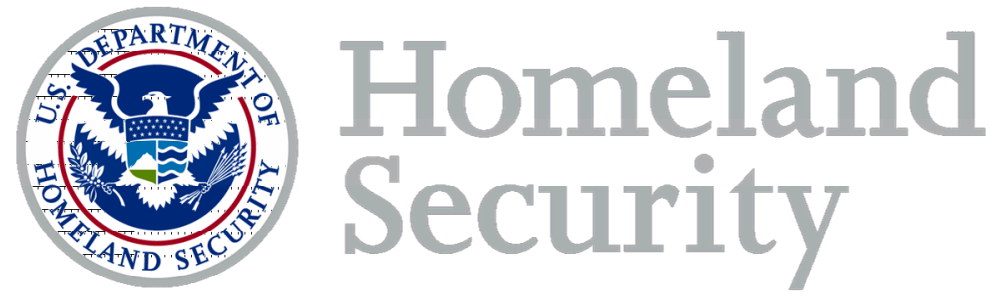

October 2006

Carl Melius*

Alix Robertson

Pam Hullinger

UCRL-TR-XXXXXX

*925-422-3753, melius1@|lnl.gov

Lawrence Livermore National Laboratory

P.O. Box 808 - Livermore, CA 94551-0808 



\section{Developing Livestock Facility Type Information from USDA Agricultural Census Data for Use in Epidemiological and Economic Models}

\section{Executive Summary}

The epidemiological and economic modeling of livestock diseases requires knowing the size, location, and operational type of each livestock facility within the US. At the present time, the only national database of livestock facilities that is available to the general public is the USDA's 2002 Agricultural Census data, published by the National Agricultural Statistics Service (http://www.nass.usda.gov/Census_of_Agriculture), herein referred to as the "NASS data." The NASS data provides facility data at the county level for various livestock types (i.e., beef cows, milk cows, cattle on feed, other cattle, total hogs and pigs, sheep and lambs, milk goats, and angora goats). However, the number and sizes of facilities for the various livestock types are not independent since some facilities have more than one type of livestock, and some livestock are of more than one type (e.g., "other cattle" that are being fed for slaughter are also "cattle on feed"). In addition, any data tabulated by NASS that could identify numbers of animals or other data reported by an individual respondent is suppressed by NASS and coded with a "D.".

To be useful for epidemiological and economic modeling, the NASS data must be converted into a unique set of facility types (farms having similar operational characteristics). The unique set must not double count facilities or animals. At the same time, it must account for all the animals, including those for which the data has been suppressed. Therefore, several data processing steps are required to work back from the published NASS data to obtain a consistent database for individual livestock operations.

This technical report documents data processing steps that were used to convert the NASS data into a national livestock facility database with twenty-eight facility types. The process involves two major steps. The first step defines the rules used to estimate the data that is suppressed within the NASS database. The second step converts the NASS livestock types into the operational facility types used by the epidemiological and economic model.

Comparison of the resulting database with an independent survey of farms in central California shows excellent agreement between the numbers of farms for the various facility types. This suggests that the NASS data are well suited for providing a consistent set of county-level information on facility numbers and sizes that can be used in epidemiological and economic models. 


\section{Introduction}

With funding from DHS, Lawrence Livermore National Laboratory (LLNL), in collaboration with several academic and federal partners, is developing a nationwide, coupled epidemiological and economic model to analyze potential response strategies to an outbreak of foot-and-mouth disease in US livestock. The model has been designed to simulate disease transmission, while simultaneously accounting for costs due to disease control measures, such as vaccination, slaughter, and livestock movement restrictions. The model simulates disease transmission and costs of control acting on individual livestock operations.

The epidemiological and economic modeling of livestock diseases requires knowledge of the operation type and size of each individual facility. At the present time, the only national database of livestock operations that is available to the general public is the published data from the 2002 Agricultural Census, referred to as the "NASS data." The NASS data provides facility data at the county level for various livestock types (i.e., beef cows, milk cows, cattle on feed, other cattle, total hogs and pigs, sheep and lambs, milk goats, and angora goats). However, the number and sizes of facilities for the various livestock types are not independent since some facilities have more than one type of livestock, and some livestock are of more than one type (e.g., "other cattle" that are being fed for slaughter are also "cattle on feed"). In addition, any data tabulated by NASS that could identify numbers of animals or other data reported by an individual respondent is suppressed by NASS and coded with a "D."

Thus, several data processing steps are required to work back from the published data to obtain a representative national database for individual livestock operations. First, estimation steps are needed to replace data that have been suppressed in the NASS data. Then, the NASS livestock types must be converted into a set of distinct and nonoverlapping types of livestock operation that can be used by the epidemiological and economic model.

This technical report documents the data processing steps that were used by LLNL to develop a national database of livestock facilities by county location for use in epidemiological and economic simulations. The report is organized into six sections. Section 2 defines the steps used to access the NASS data, and describes the structure of the single database that was compiled from the various NASS data files. Section 2 also presents the rules that were used to estimate the data that are suppressed and coded with a "D" in the NASS tables. Section 3 presents the steps used to define the unique operational facility types that are used by the epidemiological and economic model. Section 4 presents a summary of the resulting national database, including the total number of livestock facilities of each type in the US, and livestock density maps by county location. Section 5 compares the database derived from the NASS data with an independent survey of livestock in the Fresno/Kings/Tulare tri-county region of California. Section 6 discusses additional data comparisons and other directions for future work. 


\section{NASS data}

This section defines the steps used to access the NASS data, and describes the structure of the single database that was compiled from the various NASS data files. This section also presents the rules that were used to estimate the data that are suppressed and coded with a "D" in the NASS tables.

\subsection{NASS data description}

The NASS data constitute a consistent set of farm and livestock data for each county in the United States. The NASS data are presented in tables as follows:

- Rows report data by county.

- Columns report data by number and type of livestock.

- Columns are organized into pairs: the first column in each pair reports the number of farms, and the second column reports the number of animals, for the number and type of livestock.

The NASS data includes both inventory and sales of livestock. Inventory is reported as the number of livestock of each type that was present on December 31,2002, and sales is reported as the number of livestock of each type that was sold during the 2002 calendar year. LLNL used the NASS inventory data to derive a national database for use in epidemiological and economic models..

The NASS inventory data are reported by county location in over 200 files, including one file for each of the major livestock species (cattle, swine, sheep, and goats) in each of the 50 US states. LLNL downloaded these 200+ files individually from the USDA National Agricultural Statistics Service (NASS) website, www.usda.nass.gov, and compiled them into the single file, AgCensus2002DataLivestock.csv. Table 1 lists the categories for number and type of livestock that are compiled into the file AgCensus2002DataLivestock.csv. Table 1 also lists the total number of US farms for each of these livestock categories.

NASS provides a more detailed breakdown of livestock types at the state level than at the county level. In particular, NASS provides information of stages of swine operations at the state level that is not made available by county location. These data are reported in some 50 files, one for each state. As an example of NASS data that are reported at the state level, Table 2 shows the NASS data for numbers of swine in California by type and size of swine facility. 
Table 1 - Numbers of US farms by type and size categories reported by NASS $\begin{array}{ll}\text { NASS farm category (defined by type and number of livestock present) } & \text { US farms }\end{array}$

Cattle and calves (farms, 2002)

Cattle and calves $\backslash$ Farms by inventory $\backslash 1$ to 9 (farms, 2002)

Cattle and calves $\backslash$ Farms by inventory $\backslash 10$ to 19 (farms, 2002)

Cattle and calves $\backslash$ Farms by inventory $\backslash 20$ to 49 (farms, 2002)

Cattle and calves $\backslash$ Farms by inventory $\backslash 50$ to 99 (farms, 2002)

Cattle and calves \Farms by inventory \} 1 0 0 \text { to } 1 9 9 \text { (farms, 2002) }

Cattle and calves $\backslash$ Farms by inventory $\backslash 200$ to 499 (farms, 2002)

Cattle and calves $\backslash$ Farms by inventory $\backslash 500$ or more (farms, 2002)

Cattle and calves $\backslash$ Cows and heifers that had calved (farms, 2002)

Cattle and calves $\backslash$ Cows and heifers that had calved $\backslash$ Beef cows (farms, 2002)

Cattle and calves \Cows and heifers that had calved \Beef cows $\backslash 2002$ farms by inventory $\backslash 1$ to 9 (farms)

Cattle and calves \Cows and heifers that had calved \Beef cows $\backslash 2002$ farms by inventory $\backslash 10$ to 19 (farms)

Cattle and calves \Cows and heifers that had calved \Beef cows $\backslash 2002$ farms by inventory $\backslash 20$ to 49 (farms)

Cattle and calves $\backslash$ Cows and heifers that had calved \Beef cows $\backslash 2002$ farms by inventory $\backslash 50$ to 99 (farms)

Cattle and calves $\backslash$ Cows and heifers that had calved $\backslash$ Beef cows $\backslash 2002$ farms by inventory $\backslash 100$ to 199 (farms)

Cattle and calves \Cows and heifers that had calved \Beef cows $\backslash 2002$ farms by inventory $\backslash 200$ to 499 (farms)

Cattle and calves $\backslash$ Cows and heifers that had calved $\backslash$ Beef cows $\backslash 2002$ farms by inventory $\backslash 500$ or more (farms)

Cattle and calves $\backslash$ Cows and heifers that had calved $\backslash$ Milk cows (farms, 2002)

Cattle and calves $\backslash$ Cows and heifers that had calved $\backslash$ Milk cows $\backslash 2002$ farms by inventory $\backslash 1$ to 9 (farms)

Cattle and calves $\backslash$ Cows and heifers that had calved $\backslash$ Milk cows $\backslash 2002$ farms by inventory $\backslash 10$ to 19 (farms)

Cattle and calves $\backslash$ Cows and heifers that had calved $\backslash$ Milk cows $\backslash 2002$ farms by inventory $\backslash 20$ to 49 (farms)

Cattle and calves $\backslash$ Cows and heifers that had calved $\backslash$ Milk cows $\backslash 2002$ farms by inventory $\backslash 50$ to 99 (farms)

Cattle and calves $\backslash$ Cows and heifers that had calved $\backslash$ Milk cows $\backslash 2002$ farms by inventory $\backslash 100$ to 199 (farms)

Cattle and calves $\backslash$ Cows and heifers that had calved $\backslash$ Milk cows $\backslash 2002$ farms by inventory $\backslash 200$ to 499 (farms)

Cattle and calves \Cows and heifers that had calved \Milk cows $\backslash 2002$ farms by inventory $\backslash 500$ or more (farms)

Cattle and calves $\backslash$ Cattle on feed (see text) (farms, 2002)

Cattle and calves $\backslash$ Cattle on feed (see text) $\backslash 2002$ farms by inventory $\backslash 1$ to 9 (farms)

Cattle and calves $\backslash$ Cattle on feed (see text) $\backslash 2002$ farms by inventory $\backslash 10$ to 19 (farms)

Cattle and calves $\backslash$ Cattle on feed (see text) $\backslash 2002$ farms by inventory $\backslash 20$ to 49 (farms)

Cattle and calves $\backslash$ Cattle on feed (see text) $\backslash 2002$ farms by inventory $\backslash 50$ to 99 (farms)

Cattle and calves \Cattle on feed (see text) \2002 farms by inventory $\backslash 100$ to 199 (farms)

Cattle and calves $\backslash$ Cattle on feed (see text) $\backslash 2002$ farms by inventory $\backslash 200$ to 499 (farms)

Cattle and calves $\backslash$ Cattle on feed (see text) $\backslash 2002$ farms by inventory $\backslash 500$ or more (farms)

Cattle and calves $\backslash$ Other cattle (see text) (farms, 2002)

Cattle and calves $\backslash$ Other cattle (see text) $\backslash 2002$ farms by inventory $\backslash 1$ to 9 (farms)

Cattle and calves $\backslash$ Other cattle (see text) $\backslash 2002$ farms by inventory $\backslash 10$ to 19 (farms)

Cattle and calves $\backslash$ Other cattle (see text) $\backslash 2002$ farms by inventory $\backslash 20$ to 49 (farms)

Cattle and calves $\backslash$ Other cattle (see text) $\backslash 2002$ farms by inventory $\backslash 50$ to 99 (farms)

Cattle and calves $\backslash$ Other cattle (see text) $\backslash 2002$ farms by inventory $\backslash 100$ to 199 (farms)

Cattle and calves $\backslash$ Other cattle (see text) $\backslash 2002$ farms by inventory $\backslash 200$ to 499 (farms)

Cattle and calves $\backslash$ Other cattle (see text) $\backslash 2002$ farms by inventory $\backslash 500$ or more (farms)

Total hogs and pigs (farms, 2002)

Total hogs and pigs $\backslash$ Farms by inventory $\backslash 1$ to 24 (farms, 2002)

Total hogs and pigs $\backslash$ Farms by inventory $\backslash 25$ to 49 (farms, 2002)

Total hogs and pigs $\backslash$ Farms by inventory $\backslash 50$ to 99 (farms, 2002)

Total hogs and pigs \ Farms by inventory $\backslash 100$ to 199 (farms, 2002)

Total hogs and pigs $\backslash$ Farms by inventory $\backslash 200$ to 499 (farms, 2002)

Total hogs and pigs \Farms by inventory $\backslash 500$ to 999 (farms, 2002)

Total hogs and pigs $\backslash$ Farms by inventory $\backslash 1,000$ or more (farms, 2002)

Total hogs and pigs $\backslash$ Hogs and pigs used or to be used for breeding (farms, 2002)

Total hogs and pigs $\backslash$ Hogs and pigs used or to be used for breeding $\backslash 2002$ farms by inventory $\backslash 1$ to 24

Total hogs and pigs $\backslash$ Hogs and pigs used or to be used for breeding $\backslash 2002$ farms by inventory $\backslash 50$ to 99

Total hogs and pigs $\backslash$ Other hogs and pigs (farms, 2002)

Sheep and lambs inventory (see text) (farms, 2002)

Sheep and lambs inventory (see text) $\backslash 2002$ farms by inventory $\backslash 1$ to 24 (farms)

Sheep and lambs inventory (see text) $\backslash 2002$ farms by inventory $\backslash 25$ to 99 (farms)

Sheep and lambs inventory (see text) $\backslash 2002$ farms by inventory $\backslash 100$ to 299 (farms)

Sheep and lambs inventory (see text) $\backslash 2002$ farms by inventory $\backslash 300$ to 999 (farms)

Sheep and lambs inventory (see text) $\backslash 2002$ farms by inventory $\backslash 1,000$ or more (farms)

Sheep and lambs inventory (see text) $\backslash$ Ewes 1 year old or older (farms, 2002)

Milk Goats Inventory Farms

Goats-Angora-Farms

$1,018,359$

211,030

189,193

271,202

153,618

103,513

62,774

27,029

864,823

796,436

239,452

178,038

215,320

89,874

45,354

23,126

5,272

91,989

21,016

5,270

21,974

25,465

10,816

4,546

2,902

80,743

30,409

13,778

14,552

9,207

5,889

4,139

2,769

875,850

348,102

173,744

183,102

84,287

45,719

27,595

13,301

78,895

38,303

5,650

4,682

4,611

7,755

6,010

11,884

39,367

24,794

3,660

71,923

73,814

44,562

20,694

5,670

1,995

893

66,769

22,389

Source: USDA NASS

1,756 
Table 2 - Numbers of swine in California by facility type and size as reported by NASS

\begin{tabular}{|c|c|c|c|c|c|c|c|c|c|c|}
\hline Herd size & $\begin{array}{c}\text { Farrow to } \\
\text { wean } \\
\text { Farms }\end{array}$ & $\begin{array}{l}\text { Farrow to } \\
\text { wean } \\
\text { Number }\end{array}$ & $\begin{array}{l}\text { Farrow to } \\
\text { finish } \\
\text { Farms }\end{array}$ & $\begin{array}{l}\text { Farrow to } \\
\text { finish } \\
\text { Number }\end{array}$ & $\begin{array}{c}\text { Finish only } \\
\text { Farms }\end{array}$ & $\begin{array}{l}\text { Finish only } \\
\text { Number }\end{array}$ & $\begin{array}{c}\text { Farrow to } \\
\text { feeder } \\
\text { Farms }\end{array}$ & $\begin{array}{l}\text { Farrow to } \\
\text { feeder } \\
\text { Number }\end{array}$ & $\begin{array}{c}\text { Nursery } \\
\text { Farms }\end{array}$ & $\begin{array}{l}\text { Nursery } \\
\text { Number }\end{array}$ \\
\hline Any & 207 & 9,034 & 439 & 125,014 & 431 & 4,570 & 255 & 24,290 & 3 & 72 \\
\hline 1 to 24 & 147 & 1,373 & 332 & 2,136 & 404 & 2,081 & 181 & 1,305 & 3 & 72 \\
\hline 25 to 49 & 26 & (D) & 34 & 1,161 & 13 & 447 & 29 & 986 & - & - \\
\hline 50 to 99 & 16 & 1,037 & 26 & 1,947 & 6 & 382 & 21 & 1,434 & - & - \\
\hline 100 to 199 & 8 & 973 & 23 & 2,955 & 3 & 360 & 15 & (D) & - & - \\
\hline 200 to 499 & 9 & 3,256 & 11 & 3,348 & 5 & 1,300 & 6 & 1,985 & - & - \\
\hline 500 to 999 & - & - & 5 & 3,663 & - & - & 2 & (D) & - & - \\
\hline 1,000 to 1,999 & 1 & (D) & 3 & 4,120 & - & - & - & - & - & - \\
\hline 2,000 to 4,999 & - & - & 2 & (D) & - & - & - & - & - & - \\
\hline 5,000 or more & - & - & 3 & (D) & - & - & 1 & (D) & - & - \\
\hline 5,000 to 7,499 & - & - & 1 & (D) & - & - & - & - & - & - \\
\hline 7,500 or more & - & - & 2 & (D) & - & - & 1 & (D) & - & - \\
\hline
\end{tabular}

The following footnotes, headnotes, abbreviations and symbols are used throughout this table:

(D) Withheld to avoid disclosing data for individual farms.

- Represents zero.

Farm counts and inventories may be included in more than one operation type.

\subsection{Process to develop estimates for suppressed data}

Certain entries of the NASS data for number of animals are suppressed and coded as "D" in order to protect confidential business information. The process that was used to estimate the suppressed data is described by the following three steps:

\section{Step 1: Develop estimates for county totals}

Estimates were first developed within each of the NASS livestock categories that are reported at the county level. These categories are listed in Table 1. As an example, one category reported at the county level is "Cattle and calves $\backslash$ Cows and heifers that had calved $\backslash$ Beef cows):

First, for a given type of livestock and herd size category of bounded range (i.e., 1-9, 10$19, \ldots, 200-499$, but excluding the largest size range, which is unbounded) $)^{a}$ :

1.1 Check if the state total for that size facility is available. If so, assign missing data to the difference of the state total and the sum of known county data. If data are missing for more than one county in the state, assign numbers of animals to counties proportional to number of farms having missing data.

1.2 If state total is missing, assign the average herd size to be the midpoint of the size range.

Next, for the largest size range (no mid-range value available, since size range is unbounded):

\footnotetext{
${ }^{a}$ The largest NASS size categories are 500 or more head for cattle and 1,000 or more head for swine and sheep (cf. Table 1).
} 
1.3 Check if the county total is available for the sum of all size categories. If so, assign missing data to difference of total number of animals for all farms in the county and numbers of animals for farms in the county that are in smaller size categories (smaller sizes should now be defined due to the previous step). If the resulting size is less than the minimum of the range, assign the minimum value.

1.4 If the county total for the sum of all size categories is missing, check if the state total is available for the livestock type and herd size category. If so, assign missing data to the difference of the state total and the sum for counties reporting livestock inventory. If data are missing for multiple counties, assign animals to these counties proportional to the number of farms of the type and size in each of the counties. ${ }^{b}$

1.5 If the state total for the largest size category is missing, assign the missing data to be twice the minimum size of the range. Note that this is a "last resort" procedure. Fortunately, state totals for large farms were reported for most states with major livestock production (Table 3). ${ }^{\mathrm{c}}$

\section{Step 2: Fix the sum of the size subcategories}

For each county, reassign the total number of animals for a given category to be the sum of the individual size subcategories (e.g., the sum of subcategories with 1-9, 10-19, ..., and $500+$ animals). Note that Step 1.3 above reduces the likelihood that the sum will change significantly, if the sum had already been reported in the NASS tables.

\section{Step 3: Fix the state and US data}

For each of the size subcategories as well as for the livestock category as a whole, sum over all of the counties in the state and reassign the total for the given state. Then sum over the states to obtain the total for the US.

\footnotetext{
${ }^{\mathrm{b}}$ Step 1.4 for the largest size category is analogous to step 1.1 used for the smaller size categories. ${ }^{\mathrm{c}}$ Step 1.5 for the largest size category is analogous to step 1.2 used for the smaller size categories, except that no mid-range exists.
} 
Table 3 - Numbers of animals reported by NASS for farms in the largest size category

\begin{tabular}{|c|c|c|c|c|c|c|c|}
\hline State & Cattle & Beef cows & Milk cows & Cattle on feed & Other cattle & Hogs and pigs & $\begin{array}{r}\text { Sheep and } \\
\text { lambs }\end{array}$ \\
\hline Alabama & 247,918 & 40,928 & 5,033 & (D) & 91,046 & 145,632 & - \\
\hline Alaska & 7,913 & (D) & - & - & (D) & - & - \\
\hline Arizona & 703,116 & 65,994 & 150,659 & 287,800 & 437,786 & (D) & 105,809 \\
\hline Arkansas & 270,645 & 37,176 & (D) & (D) & 127,158 & 247,951 & - \\
\hline California & $4,438,463$ & 252,744 & $1,434,748$ & 519,074 & $2,298,114$ & 126,594 & 589,507 \\
\hline Colorado & $1,857,830$ & 151,036 & 75,316 & $1,062,357$ & $1,437,244$ & 720,279 & 312,286 \\
\hline Connecticut & 14,897 & - & 3,580 & (D) & (D) & - & - \\
\hline Delaware & 3,723 & - & (D) & - & (D) & 7,388 & - \\
\hline Florida & 918,365 & 427,147 & 116,235 & - & 193,702 & (D) & (D) \\
\hline Georgia & 221,636 & 21,011 & 33,859 & - & 77,636 & 271,607 & (D) \\
\hline Hawaii & 115,668 & 58,338 & 6,341 & (D) & 43,061 & 5,312 & (D) \\
\hline Idaho & $1,371,120$ & 139,471 & 318,022 & 299,971 & 731,976 & 8,591 & 211,148 \\
\hline Illinois & 244,071 & 5,003 & 11,883 & 124,366 & 171,508 & $3,352,399$ & (D) \\
\hline Indiana & 121,750 & 1,850 & 40,930 & 16,804 & 54,612 & $2,820,959$ & (D) \\
\hline lowa & $1,063,408$ & 27,236 & 33,566 & 606,648 & 823,391 & $13,263,736$ & 43,787 \\
\hline Kansas & $3,813,504$ & 124,521 & 70,262 & $2,223,850$ & $3,223,386$ & $1,374,702$ & 13,295 \\
\hline Kentucky & 278,048 & 19,454 & (D) & 2,650 & 151,562 & 304,354 & - \\
\hline Louisiana & 147,203 & 53,869 & 2,547 & - & 20,342 & 5,286 & - \\
\hline Maine & 16,996 & - & 3,999 & (D) & 3,879 & - & - \\
\hline Maryland & 35,118 & - & 9,039 & (D) & 10,761 & (D) & (D) \\
\hline Massachusetts & 4,128 & - & (D) & - & (D) & (D) & - \\
\hline Michigan & 311,090 & (D) & 84,103 & 66,120 & 132,801 & 780,267 & 12,779 \\
\hline Minnesota & 420,141 & 8,642 & 52,781 & 150,763 & 249,393 & $5,534,015$ & 14,445 \\
\hline Mississippi & 182,457 & 29,099 & 2,660 & - & 95,096 & 285,858 & - \\
\hline Missouri & 694,764 & 91,157 & 6,464 & 28,096 & 328,829 & $2,493,691$ & - \\
\hline Montana & $1,200,925$ & 446,640 & (D) & 52,884 & 402,647 & 149,671 & 109,767 \\
\hline Nebraska & $3,930,038$ & 461,513 & 22,131 & $2,173,979$ & $2,906,115$ & $2,329,322$ & 11,625 \\
\hline Nevada & 358,020 & 156,713 & 23,734 & 19,463 & 111,014 & (D) & 67,917 \\
\hline New Hampshire & 6,587 & - & (D) & - & (D) & - & - \\
\hline New Jersey & 3,815 & - & (D) & - & - & 5,952 & - \\
\hline New Mexico & $1,157,022$ & 176,068 & 308,530 & 126,950 & 512,933 & - & 114,482 \\
\hline New York & 419,167 & - & 153,036 & 10,010 & 129,718 & 51,194 & 6,847 \\
\hline North Carolina & 95,869 & 9,760 & 9,800 & - & 30,699 & $9,803,370$ & - \\
\hline North Dakota & 526,552 & 59,899 & 4,471 & 30,069 & 173,834 & 92,530 & 20,300 \\
\hline Ohio & 185,347 & 4,222 & 25,570 & 45,591 & 94,194 & $1,024,696$ & 8,684 \\
\hline Oklahoma & $1,971,772$ & 163,279 & 25,702 & 343,350 & $1,432,604$ & $2,183,182$ & (D) \\
\hline Oregon & 795,957 & 209,255 & 61,128 & 71,226 & 346,232 & (D) & 96,476 \\
\hline Pennsylvania & 179,608 & - & 33,678 & 20,608 & 80,720 & 971,534 & 5,100 \\
\hline Rhode Island & - & - & - & - & - & - & - \\
\hline South Carolina & 60,419 & 6,949 & 3,235 & (D) & 15,621 & 251,158 & - \\
\hline South Dakota & $1,643,475$ & 282,618 & 21,242 & 276,715 & 760,971 & $1,123,301$ & 116,338 \\
\hline Tennessee & 237,377 & 17,112 & 5,594 & - & 125,104 & 160,466 & \\
\hline Texas & $6,842,905$ & 836,077 & 184,149 & $2,644,450$ & $4,825,394$ & 856,624 & 534,372 \\
\hline Utah & 429,949 & 91,070 & 39,941 & 33,363 & 181,730 & 659,169 & 233,579 \\
\hline Vermont & 84,865 & - & 27,337 & (D) & 20,026 & & (D) \\
\hline Virginia & 280,996 & 22,493 & 8,321 & 16,218 & 115,769 & 387,054 & 3,764 \\
\hline Washington & 650,052 & 47,893 & 150,214 & 197,095 & 360,275 & 13,564 & 11,990 \\
\hline West Virginia & 34,191 & 1,685 & (D) & 1,840 & 11,776 & (D) & - \\
\hline Wisconsin & 620,750 & 3,120 & 160,052 & 19,178 & 218,625 & 278,781 & 3,531 \\
\hline Wyoming & 795,410 & 282,748 & - & 69,121 & 307,901 & 104,635 & 363,422 \\
\hline
\end{tabular}

Steps 1 through 3 are applied to each of the livestock categories within the NASS data, i.e., beef cows, milk cows, cattle on feed, other cattle, total hogs and pigs (but not swine used for breeding, which was not used), sheep and lambs, milk goats, and Angora goats.

To illustrate the procedure, Table 4 presents estimates for suppressed data for cattle in Fresno County, California. These estimates were calculated as follows: 
1. The inventory of cattle on feed was estimated for three large feedlots in Fresno County using California state and county data for cattle on feed in large feedlots. Based on the difference between state and reported county inventories, there was an average of 11,718 cattle on feed for each of fourteen feedlots in California for which livestock inventories were suppressed. Since there were three large feedlots in Fresno County, the estimated number of cattle on feed in Fresno County was 35,154 .

2. Similarly the numbers of milk cows on small farms (in the subcategories of farms with 1-9 and 20-49 milk cows) were calculated based on the difference of state and reported county totals for numbers of farms and numbers of milk cows on farms in these size ranges.

Table 4 - Numbers of cattle in Fresno, California as reported by NASS and with suppressed data replaced by estimates

\begin{tabular}{|c|c|c|c|c|}
\hline Farm size / type & Milk cows & Beef cows & Cattle on feed & "Other cattle" \\
\hline \multicolumn{5}{|c|}{ Number of animals reported by NASS } \\
\hline 1 to 9 & (D) & 1,348 & 87 & 1,358 \\
\hline 10 to 19 & 146 & 1,339 & 45 & 1,594 \\
\hline 20 to 49 & (D) & 2,805 & - & 1,797 \\
\hline 50 to 99 & 184 & 2,201 & - & 2,162 \\
\hline 100 to 199 & 986 & 3,112 & - & 3,925 \\
\hline 200 to 499 & 10,386 & 7,726 & - & 11,798 \\
\hline 500 or more & 78,757 & 4,891 & (D) & 259,913 \\
\hline all & 90,550 & 23,422 & (D) & 282,547 \\
\hline \multicolumn{5}{|c|}{ Number of animals reported by NASS with suppressed data replaced by estimates } \\
\hline 1 to 9 & 46 & 1,348 & 87 & 1,358 \\
\hline 10 to 19 & 146 & 1,339 & 45 & 1,594 \\
\hline 20 to 49 & 22 & 2,805 & - & 1,797 \\
\hline 50 to 99 & 184 & 2,201 & - & 2,162 \\
\hline 100 to 199 & 986 & 3,112 & - & 3,925 \\
\hline 200 to 499 & 10,386 & 7,726 & - & 11,798 \\
\hline 500 or more & 78,757 & 4,891 & 35,151 & 259,913 \\
\hline all & 90,527 & 23,422 & 35,283 & 282,547 \\
\hline
\end{tabular}




\section{Redefining types of farm facilities}

This section presents the steps that were used to define the unique operational facility types that are used by the epidemiological and economic model. These steps also define estimates for the size of individual operations of each type. A separate process was used to define unique operational facilities for each of the major livestock types. Section 3.1 reports steps used for defining cattle facilities, Section 3.2 reports steps for defining swine facilities, Section 3.3 reports steps for defining sheep facilities, and Section 3.4 reports steps for defining facilities with goats.

\subsection{Redefining types of cattle facilities}

The NASS data for cattle were redefined based on the following observations on the NASS data.

1. The NASS data divides all cattle and calves into three distinct types:
a. milk cows,
b. beef cows, and
c. other cattle.

2. The "other cattle" type includes calves and replacement heifers on dairy ranches; calves, bulls, and heifers on cow-calf operations; and steers and heifers on feedlots.

3. NASS also reports cattle on feed. These are cattle that were fed for direct shipment to slaughter on the survey date of December 31,2002. Most cattle on feed are steers and heifers, all of whom are "other cattle," i.e., cattle other than beef cows and milk cows. Therefore "cattle on feed" is a subset of "other cattle."

4. There is overlap in farm types since, e.g., farms that have dairy cows may also have other cattle including dairy replacement heifers and calves.

5. NASS further divides cattle farms in each category into size ranges of 1-9, 10-19, 20-49, 50-99, 100-199, 200-499, and 500 or more cattle of the specified type.

6. The meaning of farm size category depends on the type of livestock. For example, a beef cow-calf operation with 20 cows, 17 calves, and one bull belongs to both of the following size subcategories:

a. 20 to 49 beef cows, and

b. 10 to 19 other cattle.

7. Due to the overlap between farm types in the NASS data, only three types of farms are distinctly identified by the reported livestock inventory:

a. Presence of beef cows identifies cow-calf operations, since beef cows are present on all cow-calf operations and are seldom present on either dairies or feedlots;

b. Presence of milk cows identifies dairies; and

c. Presence of large numbers of cattle on feed identifies feedlots.

8. A fourth type of farm is indirectly identified from the difference between the number of cattle farms and the sum of dairy, cow-calf, and feedlot type farms. Farms of this type (without either breeding cattle or cattle on feed) include stocker grazing operations and specialized dairy calf raisers. 
Based on the above observations, the following rules were developed to redefine the NASS data for cattle. Each of the rules for defining the operational types was applied on a county by county basis, and within each size subcategory of 1-9, 10-19, 20-49, 50-99, 100-199, 200-499, and 500 or more cattle.

1. Distinct farm types were identified:

a. Farms with milk cows were classified as "dairies."

b. Farms with cattle on feed were classified as "feedlots."

c. Of the total number of cattle farms, the farms not categorized as either "dairies" or "feedlots" were categorized as "grazers."

d. $\quad$ Farms with beef cows were classified as cow-calf operations.

2. Feedlots were removed from the category of "other cattle," and the residual was defined as the "remaining others" category.

3. Farm sizes were resized to include all cattle assumed to be present on each farm.

a. Farms with milk cows ("dairies") were resized to include one calf or replacement heifer for each milk cow. Cattle were taken from the "remaining others" category in the same size subcategory. If insufficient animals were available, all the available animals from that size subcategory were taken. Dairy farms were reassigned to the next larger size subcategory as needed when animals were added. Farms in the "remaining others" category were reassigned to the next smaller size subcategory, as needed, when animals were removed.

b. Farms with beef cows ("cow calf" operations) were resized to include 0.5 other cattle for each beef cow, and these cattle were subtracted from the "remaining others." Beef cow calf farms were reassigned to the next larger size subcategory as needed when animals were added. Farms in the "remaining others" category were reassigned to the next smaller size subcategory as needed when animals were removed. The ratio of 1.5 cattle to cows was chosen to represent an annual average for the number of calves that would be present on cow-calf operations, based on calf weaning at six months.

4. The "grazers" category was subdivided into "cow/calf," "stocker," and "dairy calf ranch" categories.

a. Stockers were taken to be the remainder of the "grazers" that were not "cow/calf" operations. If the number of stocker operations produced by the subtraction was less than zero, it was set to zero. This happened occasionally for the small herds, and is possibly due to the fact that small herds tend to have multiple types of cattle grazing and feeding operations.

b. The "stockers" category was further subdivided into "dairy calf ranch" operations (denoted "DCalfHeifer") and remaining stockers. The number of dairy calf ranches was estimated by multiplying the number of large dairies (those with more than 500 milk cows) by the factor of seven calf ranches per 100 large dairies. 
Finally, the dairy, feedlot, cow/calf, dairy calf ranch, and stocker operations were subdivided by sizes into large, medium, small, and backyard size subcategories.

1. For all facility types, the smallest size subcategory (with 1 to 9 animals of the specified type) was assigned to backyards:

a. Dairies with 1 to 9 animals were classified as "backyard dairy."

b. Cow calf, stocker, and feedlot facilities with fewer than ten animals were all classified as "backyard beef."

2. Farms with more than 500 animals (the maximum size range reported by NASS at the county level) were assigned to the "large" category.

3. For dairies, farms with 200 to 499 animals were assigned to the "medium" size subcategory.

4. For all facility types, farms not assigned to the large, medium, or backyard size subcategories were assigned to the "small" size subcategory.

\subsection{Redefining types of swine facilities}

The NASS data for swine (total hogs and pigs) were mapped into the following facility operation types: farrow to wean, nursery, farrow to feed, swine finisher, and farrow to finish. These facility operations were further subdivided into large, small, and backyard size subcategories.

The types of swine facilities were redefined based on the following observations on the NASS data.

1. The NASS data divides swine facilities into groups by stage of production. Although the NASS facility definitions allow some overlap of production stages, we assumed that the NASS data represent three stages of production that are typically non-overlapping, as follows: piglets in the "farrow to wean" stage, weaned pigs to 50-lb feeders in the "nursery" stage, feeder pigs to market hogs in the "swine finisher" stage.

2. In addition, NASS reports two types of swine operations that combine multiple stages of production. These are the "farrow to feeder" and "farrow to finish" operations.

3. NASS also reports the number of swine used for breeding. Swine used for breeding are primarily sows that are present as a small subset of the total number of swine on farms that conduct breeding along with other operations, i.e., farrow to wean, farrow to feeder, and farrow to finish farms. The NASS data does not distinguish the number of sows from the number of other swine on these facilities.

4. NASS divides the swine facilities of each type into size subcategories (1-24, 2549, 50-99, 100-199, 200-499, 500-999, and 1000 or more swine).

5. NASS tabulates the number of farms and the number of swine for the five distinct types of swine facility: farrow to wean, nursery, farrow to feed, swine finisher, and farrow to finish. However, these data are only provided at the state level, so the county locations are withheld from the public. 
Based on the above, the following rules were developed to redefine the NASS data for swine. Each of the rules for defining the operational types was applied on a county by county basis.

First, farms with swine of any kind were subdivided into large, small, and backyard size subcategories, as follows:

1. Farms with 1 to 24 swine were assigned to the "backyard" size subcategory.

2. Farms with more than 1,000 swine (the maximum size range available at the county level) were assigned to the "large" size subcategory.

3. The remaining farms were assigned to the "small" size subcategory.

Next, the swine farms in each size category were subdivided into the five operational types: farrow to wean, nursery, farrow to feed, swine finisher, and farrow to finish. The state breakdown by operation was used to estimate the breakdown at the county level, as follows:

1. The fraction of the number of farms of each type within a county was taken to be the same as that at the state level.

2. In treating small numbers of farms in a county, for breaking ties, farrow to finish gets precedence, then swine finisher, then farrow to feed, then farrow to wean, then nurseries.

3. Backyard operations were not subdivided by operational type.

\subsection{Redefining types of sheep facilities}

The types of sheep facilities were redefined based on the following observations on the NASS data.

1. The NASS county data tabulates the total number of sheep facilities and number of sheep in each county.

2. The NASS data divides sheep farms into size ranges of 1-24, 25-99, 100-299, 300-999, and 1,000 or more sheep present on the farm.

Based on the above, the following rules were developed to redefine the NASS data for sheep. Each of the rules for defining the operational types was applied on a county by county basis.

Farms with sheep of any kind (sheep and lambs) were subdivided into large, small, and backyard size subcategories, as follows:

1. The smallest farms (with 1 to 24 sheep) were assigned to the "backyard" size subcategory.

2. Farms with more than 1,000 sheep (the maximum size range available at the county level) were assigned to the "large" size subcategory. 
3. The remaining farms were assigned to the "small" size subcategory.

\subsection{Redefining types of goat facilities}

The types of goat facilities were redefined based on the following observations on the NASS data.

1. The NASS data tabulates the total number of goat facilities and number of goats in various counties, but not all.

2. NASS tabulates separate data for milk goats and Angora goats.

3. NASS does not divide goat farms into size ranges.

Based on the above, the following rules were developed to redefine the NASS data for goats. Each of the rules for defining the operational types was applied on a county by county basis.

1. Milk goat and Angora goat facilities were combined into one goat facility type.

2. The combined goat facility type was subdivided into backyard and remainder.

a. The average backyard size was taken to be 10 goats.

b. The fraction of backyard goat farms to the total number of goat farms in the county was taken to be the ratio of the assumed average backyard size (10 goats) to the average goat farm size in the county.

3. The remaining goat farms not assigned to the "backyard" category were assigned to the general goat category.

\section{Results}

The redefinition of the NASS data resulted in twenty-eight facility types (twelve cattle, eleven swine, three sheep, and two goat). The resulting facility types, along with the total number of farms and animals within the continental US represented by each facility type, is presented in Table 5. The geographic distribution of farm animals by facility type and county location within the US is shown in Figures 1 through 5. 
Table 5 - Number of farms and corresponding number of animals in the US by the twenty-eight facility types derived from the NASS 2002 Agricultural Census data

\begin{tabular}{|c|c|c|c|c|}
\hline Facility Type & Farms & Animals & $\begin{array}{l}\text { Size } \\
\text { Range }\end{array}$ & Description \\
\hline Dairy(L) & 5,957 & $6,833,149$ & $>500$ & Large milk cows plus calves \\
\hline Dairy(M) & 9,034 & $2,444,784$ & $200-500$ & Medium-size milk cows plus calves \\
\hline Dairy(S) & 56,642 & $4,641,644$ & $10-200$ & Large milk cows plus calves \\
\hline Dairy(B) & 20,298 & 91,013 & $<10$ & Backyard milk cows plus calves \\
\hline Feedlot(L) & 2,768 & $11,554,023$ & $>500$ & Large cattle on feed \\
\hline Feedlot(S) & 47,549 & $3,218,805$ & $10-500$ & Small cattle on feed \\
\hline CowCalf(L) & 5,479 & $5,942,172$ & $>500$ & Large beef cows plus calves \\
\hline CowCalf(S) & 489,194 & $30,375,838$ & $10-500$ & Small beef cows plus calves \\
\hline Stocker(L) & 10,611 & $9,065,378$ & $>500$ & $\begin{array}{l}\text { Remaining cattle not beef cows, milk } \\
\text { cows, cattle on feed. Excludes } \\
\text { calves moved to dairies and cow/calf } \\
\text { operations. Excludes stockers } \\
\text { reassigned to dairy calf/heifer } \\
\text { operations. }\end{array}$ \\
\hline Stocker(S) & 152,917 & $13,044,973$ & $10-500$ & $\begin{array}{l}\text { Remaining cattle not beef cows, milk } \\
\text { cows, cattle on feed. Excludes } \\
\text { calves moved to dairies and cow/calf } \\
\text { operations. }\end{array}$ \\
\hline DCalfHeifer(L) & 83 & $1,007,064$ & $>500$ & $\begin{array}{l}\text { Calf ranches, large stocker } \\
\text { operations having large dairies in the } \\
\text { immediate area }\end{array}$ \\
\hline $\operatorname{Beef}(B)$ & 190,727 & $1,543,662$ & $<10$ & $\begin{array}{l}\text { Backyard beef cattle (combined } \\
\text { cow/calf, feedlot, and stocker } \\
\text { operations) }<10 \text { animals }\end{array}$ \\
\hline SwineFarFin(L) & 3,503 & $15,522,560$ & $>1000$ & Large farrow to finish operations \\
\hline SwineFinish(L) & 5,841 & $24,699,233$ & $>1000$ & Large finishing operations \\
\hline SwineFFeeder(L) & 321 & $1,443,780$ & $>1000$ & Large farrow to feeder operations \\
\hline SwineNursery(L) & 1,361 & $5,896,355$ & $>1000$ & Large nursery operations \\
\hline SwineFWean(L) & 855 & $4,676,862$ & $>1000$ & Large farrow to wean operations \\
\hline SwineFarFin(S) & 12,490 & $3,417,573$ & $25-1000$ & Small farrow to finish operations \\
\hline SwineFinish(S) & 11,076 & $3,066,792$ & $25-1000$ & Small finishing operations \\
\hline SwineFFeeder(S) & 2,854 & 685,201 & $25-1000$ & Small farrow to feeder operations \\
\hline SwineNursery(S) & 512 & 188,728 & $25-1000$ & Small nursery operations \\
\hline SwineFWean(S) & 1,677 & 402,903 & $25-1000$ & Small farrow to wean operations \\
\hline Swine(B) & 38,153 & 256,378 & $<25$ & All swine operations $<25$ animals \\
\hline Sheep(L) & 891 & $3,031,163$ & $>1000$ & Large sheep farms \\
\hline Sheep(S) & 28,325 & $2,911,989$ & $25-1000$ & Small sheep farms \\
\hline Sheep(B) & 44,459 & 392,754 & $<25$ & Backyard sheep $<25$ animals \\
\hline Goats & 4,596 & 403,982 & $>10$ & $\begin{array}{l}\text { All goat operations excluding } \\
\text { backyard goats }\end{array}$ \\
\hline Goats(B) & 19,774 & 157,100 & $\sim 10$ & $\begin{array}{l}\text { Backyard goats having average of } \\
10 \text { or less goats }\end{array}$ \\
\hline
\end{tabular}



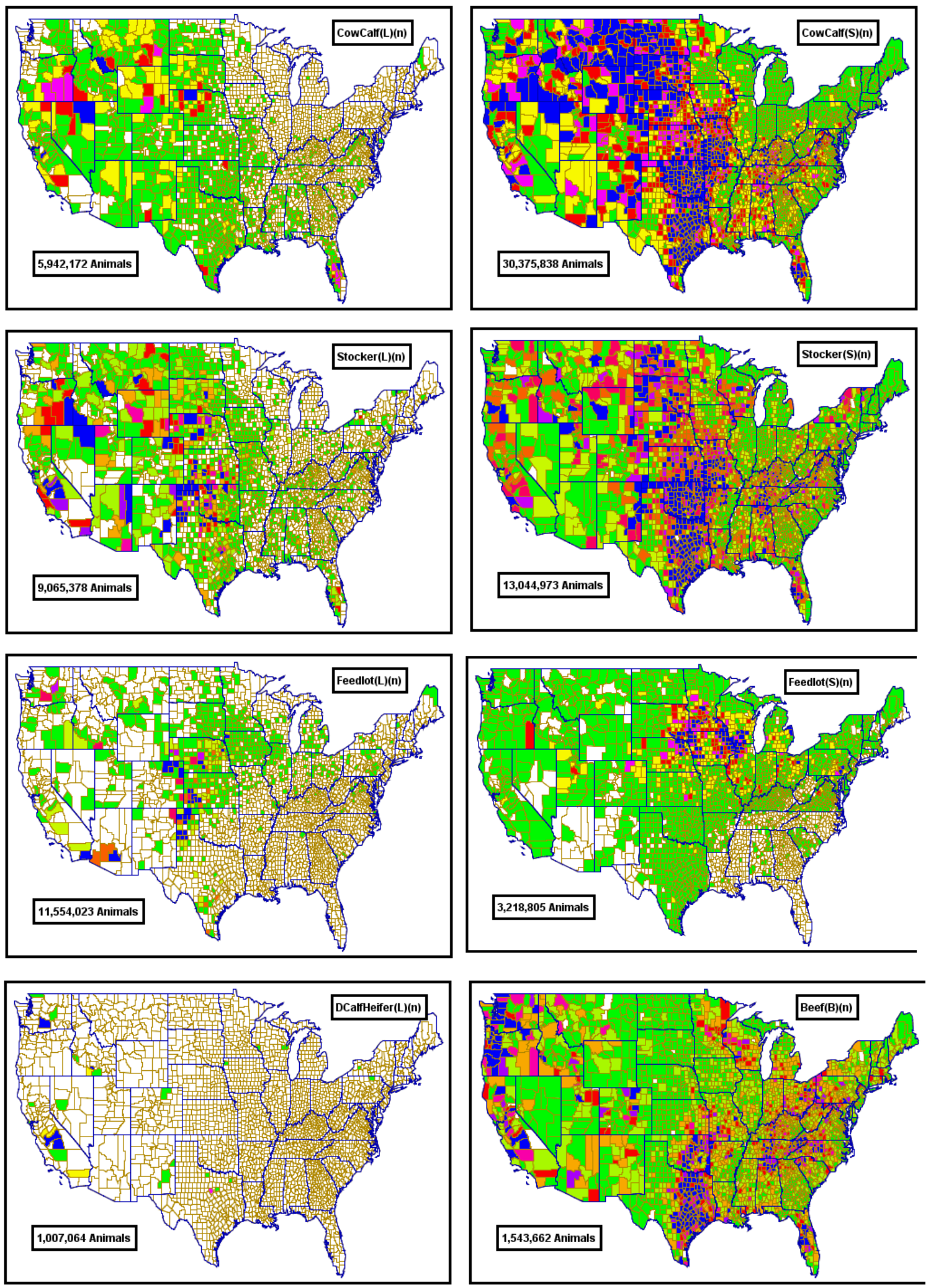

Figure 1 - Distribution of beef cattle facilities in the US (number of animals by county) 

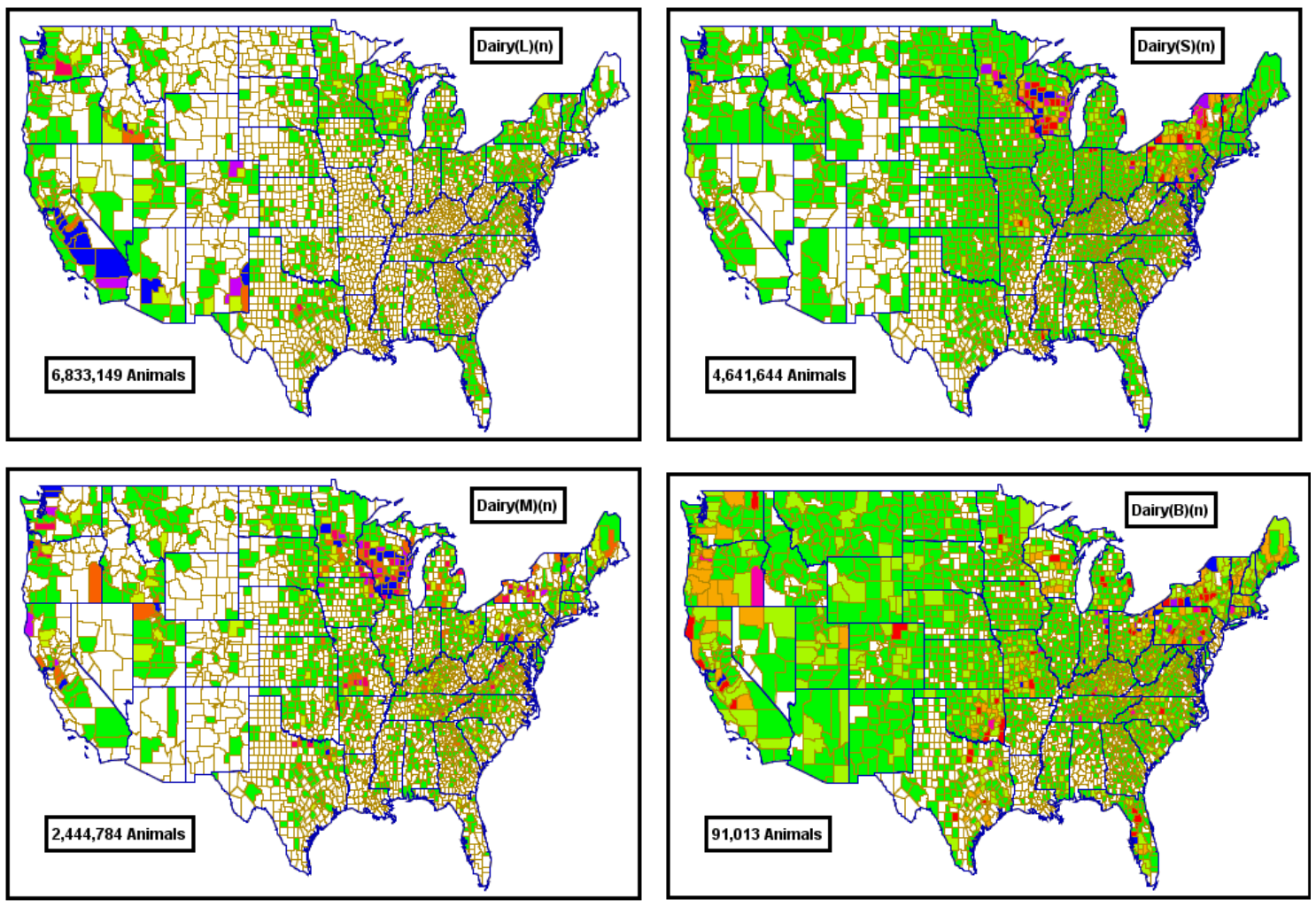

Figure 2 - Distribution of dairy facilities in the US (number of animals by county) 

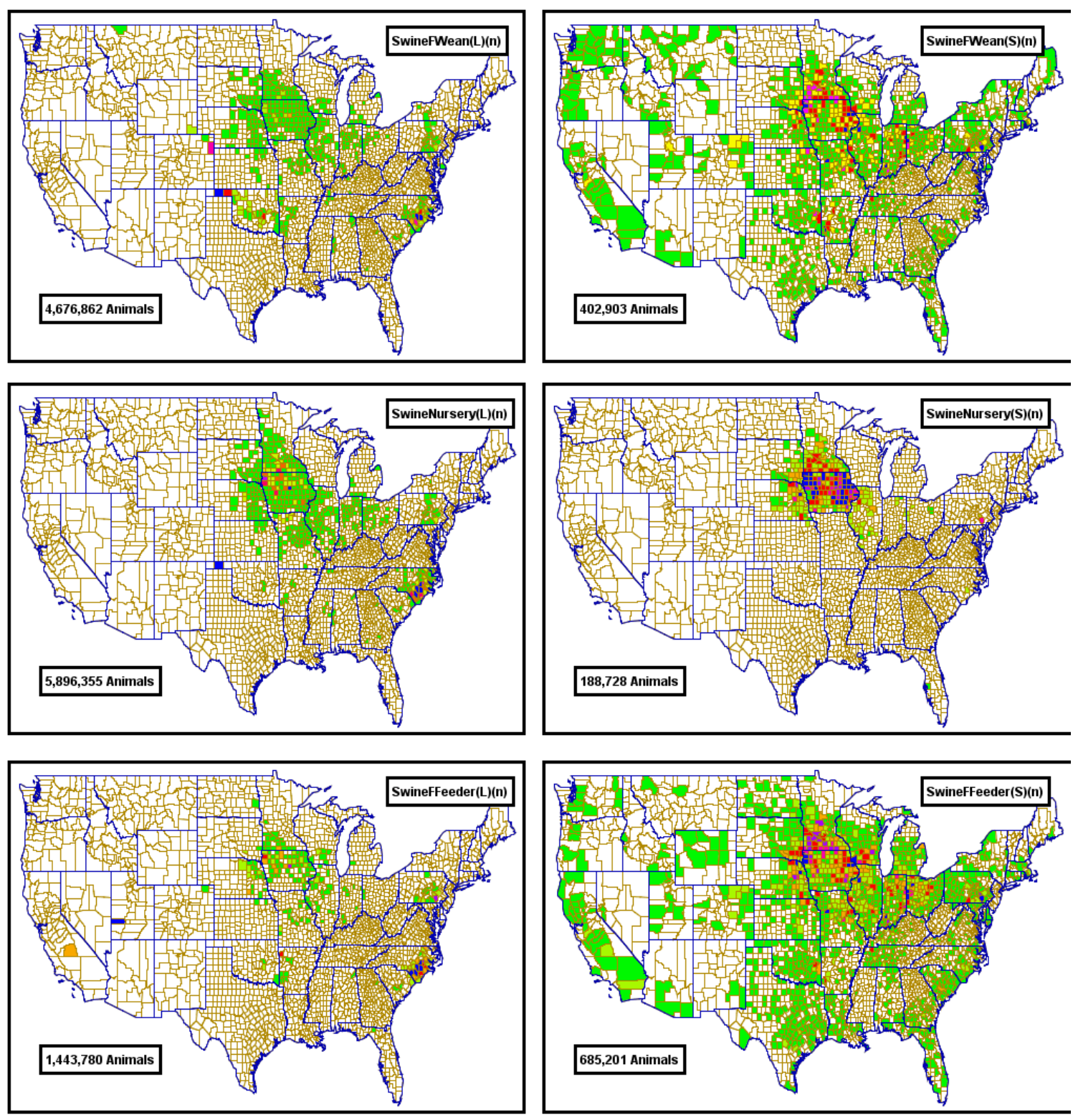

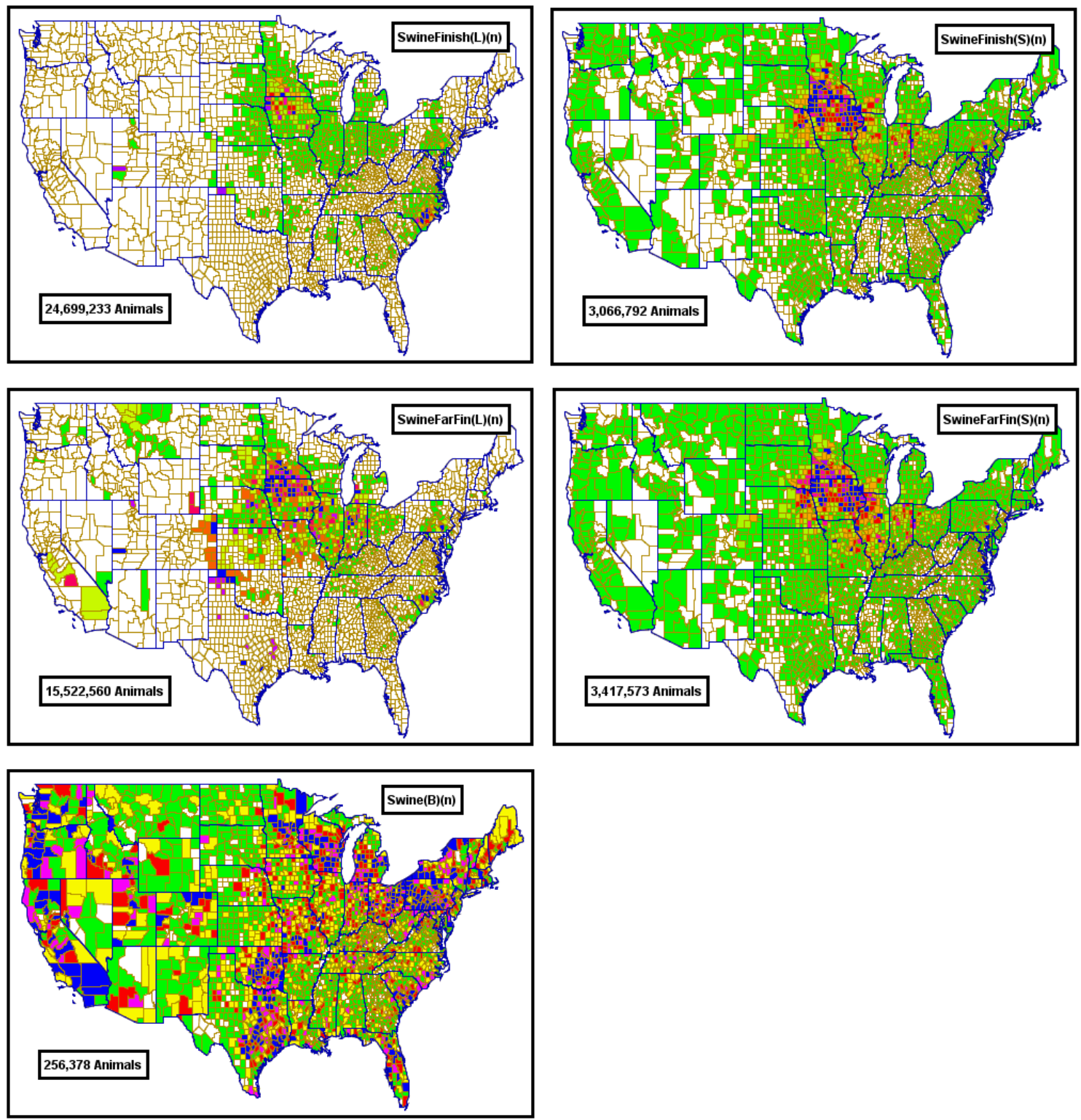

Figure 3 - Distribution of swine facilities in the US (number of animals by county). 

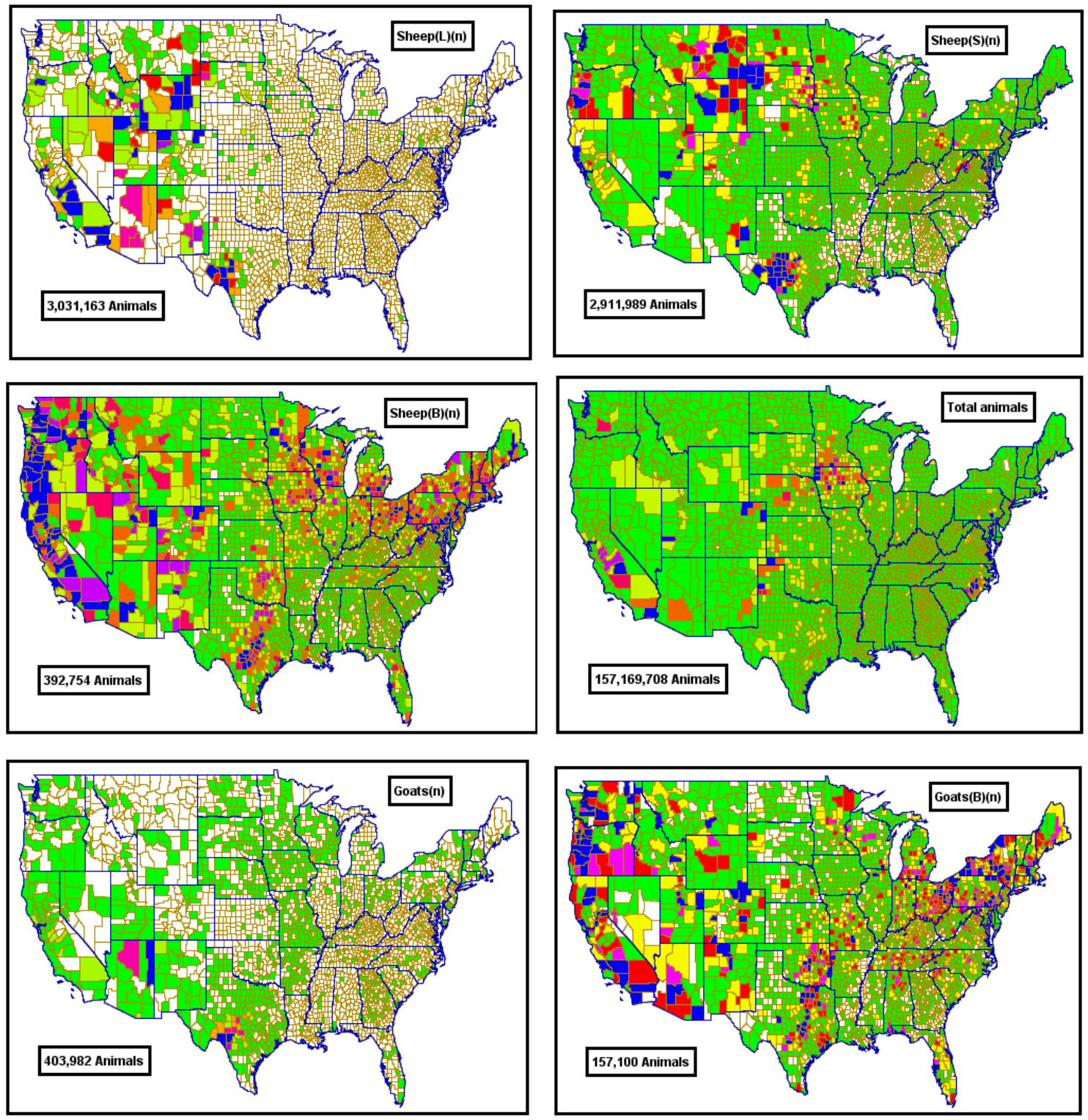

Figure 4 - Distribution of sheep and goat facilities in the US (number of animals by county) 


\section{Comparison to survey data}

In this section, we compare the resulting database derived from the NASS data with a survey of farms in the Central Valley of California undertaken by Bates et al. (2001). The survey data represents the tri-county region of Kings, Fresno, and Tulare County, California. Bates et al. defined 11 categories of various species types and size ranges, representing dairy, beef, dairy calf/heifer, swine, sheep, and goats. Dairy size ranges defined by Bates et al. are fewer than 1,000 cows, 1,000 to 2,000 cows, and more than 2,000 cows. Hence all dairies in the Bates survey fall in the range of the largest dairy size category defined by the NASS data (more than 500 cows). Similarly, the size ranges that were defined by Bates et al. for swine are fewer than 2,000 swine, and more than 2,000 swine. Hence both fall within the largest size category in the NASS data of more than 1,000 swine. In addition, in the Bates data, backyards represent premises with 10 or fewer animals of any kind, while for the database derived from the NASS data, backyards are premises with fewer than ten dairy or beef cows, or fewer than 25 swine, or fewer than 25 sheep, or fewer than 20 goats. No attempt was made to account for double counting of backyards (and larger herds) due to multiple species on single premises in the database derived from the NASS data.

To enable comparison between datasets, each set of data was normalized to a consistent set of facility types.

For data reported by Bates et al. (2001), the comparison dataset was defined as follows:

1. The facility type "dairy" was defined to represent the sum of dairies (in size ranges of fewer than 1,000 cows, 1,000 to 2,000 cows, and more than 2,000 cows).

2. The facility type "beef" was defined to represent the sum of beef herds (in size categories of fewer than 250 cattle, and more than 250 cattle) and dairy calf/heifer ranches (in size categories of fewer than 250 cattle and more than 250 cattle).

3. The facility type "swine" was defined to represent the sum of swine facilities (in size ranges of fewer than 2,000 swine and more than 2,000 swine).

4. The facility type "sheep" was defined to represent facilities with sheep.

5. The facility type "goats" was defined to represent facilities with goats.

6. The facility type "backyards" was defined to represent premises with fewer than 10 animals (cattle, swine, sheep, and/or goats), which were classified as backyards by Bates et al. (2001).

For the database derived from the NASS data, the comparison dataset was defined as follows:

1. The facility type "dairy" was defined to represent the sum of the small, medium, and large dairies (Dairy(S), Dairy(M) and Dairy(L)) and to exclude the backyard dairies (Dairy(B)).

2. The facility type "beef" was defined to represent the sum of the small, medium, and large cow calf, stocker, feedlot, and dairy calf facilities (Cow/Calf(S), Cow/Calf(L), Stocker(S), Stocker(L), Feedlot(S), Feedlot(L), and Dairy 
Calf/Heifer(L)) and to exclude backyard dairy and beef herds (Dairy(B) and $\operatorname{Beef}(\mathrm{B}))$.

3. The facility type "swine" was defined to represent the sum of small and large farrow to wean, nursery, farrow to feeder, swine finisher, and farrow to finish facilities (SwineFWean(S), SwineFWean(L), SwineNursery(S), SwineNursery(L), SwineFFeeder(S), SwineFFeeder(L), SwineFinish(S), SwineFinish(L), SwineFarFin(S), SwineFarFin(L)) and to include 50 percent of the backyard swine herds (Swine(B)).

4. The facility type "sheep" was defined to represent the sum of small and large sheep herds $(\operatorname{Sheep}(\mathrm{S})$ and Sheep(L)) and to include 50 percent of the backyard sheep herds (Sheep(B)).

5. The facility type "goats" was defined to represent the goat herds (Goats) plus 50 percent of the backyard goat herds (Goats(B)).

Table 6 compares survey results from the combined Fresno-Kings-Tulare tri-county region of California to the database derived here from the NASS data. Overall, the comparisons indicate remarkably good agreement, both in the total number of farms and in the breakup by species type. The number of dairies and swine facilities is nearly identical. The agreement with respect to the fraction assigned to backyards is also quite good. The overall number of farms is 14 percent larger for the NASS data, which reported 2,562 premises vs. 2,238 in the Bates et al. (2001) survey. Some of the NASS farms could represent double counting of premises that reported multiple species.

Table 6 - Comparison of the database derived from the NASS data and survey data reported by Bates et al. (2001) for the Fresno-Kings-Tulare tri-county region of California

\begin{tabular}{|l|r|r|}
\hline Facility Type & Bates & NASS \\
\hline Backyard & 788 & 817.5 \\
\hline Beef & 693 & 845 \\
\hline Dairy & 547 & 546 \\
\hline Swine & 79 & 79.5 \\
\hline Sheep & 69 & 171 \\
\hline Goats & 62 & 103 \\
\hline Total & 2,238 & 2,562 \\
\hline
\end{tabular}




\section{Conclusions and directions for future work}

To determine the accuracy, consistency, and thoroughness of the database derived here from the NASS data, it is important to compare with other survey data. In the previous section, we compared our data with independent survey data from central California. The database derived from the NASS data appears to provide a complete and consistent set of livestock facilities for the central California region. However future work should entail comparisons with other surveys, such as that developed for North Carolina. Comparisons with various regions will help identify any inconsistencies as well as the degree of completeness in the various data.

In addition, the NASS data only reports the locations of livestock facilities to within the county. Ultimately, one would like to have geospatial locations (including latitude and longitude and premises boundaries) of individual farms for the entire United States. Although some of these data are available for limited areas of the United States, incorporating these data into the database derived from the NASS data will require reconciliation of differences in the different national (NASS) and local surveys.

A further question that should be addressed is the impact of precise geographic locations of livestock premises on the epidemiological and economic model results. This question is being investigated by comparison of model results for the NASS data with random vs. non-random assignments of premises locations within counties in Texas. Findings of the study to date indicate that epidemiological model results for foot-and-mouth disease are relatively insensitive to precise locations within the county. However, further work is needed for other regions, especially in the western states, where counties are larger.

A similar procedure to the one outlined above is being applied to the NASS data for the poultry industry. In particular, the process described in Section 2 is being used to estimate the data for chicken and turkey operations that is suppressed by NASS to protect privacy.

\section{References}

Bates TW, Thurmond MC, Carpenter TE, 2001, Direct and indirect contact rates among beef, dairy, goat, sheep, and swine herds in three California counties, with reference to control of potential foot-and-mouth disease transmission, American Journal of Veterinary Research, 62 (7): 1121-1129.

United States Department of Agriculture (USDA), 2002 Census of Agricultural Census, National Agricultural Statistics Service (http://www.nass.usda.gov/Census_of_Agriculture). 